\title{
Rapamycin inhibits mSin 1 phosphorylation independently of MTORC1 and MTORC2
}

\author{
Yan Luo ${ }^{1,2,3, *}$, Lei Liu ${ }^{2, *}$, Yang Wu ${ }^{1,2}$, Karnika Singh ${ }^{2}$, Bing Su ${ }^{4}$, Nan Zhang ${ }^{1}$, \\ Xiaowei Liu ${ }^{1}$, Yangmei Shen ${ }^{1}$, Shile Huang ${ }^{2,3}$ \\ ${ }^{1}$ State Key Laboratory of Biotherapy/Collaborative Innovation Center of Biotherapy, West China Hospital, Sichuan University, \\ Chengdu 610041, Sichuan, People's Republic of China \\ ${ }^{2}$ Department of Biochemistry and Molecular Biology, Louisiana State University Health Sciences Center, Shreveport, LA \\ 71130-3932, USA \\ ${ }^{3}$ Feist-Weiller Cancer Center, Louisiana State University Health Sciences Center, Shreveport, LA 71130-3932, USA \\ ${ }^{4}$ Department of Immunobiology, Yale University School of Medicine, New Haven, CT 06520, USA \\ *These authors have contributed equally to this work
}

Correspondence to:

Shile Huang, e-mail: shuan1@lsuhsc.edu

Keywords: Rapamycin, mTOR, mSin 1, raptor, rictor

Received: November 19,2014 Accepted: December 21, $2014 \quad$ Published: January 30, 2015

\section{ABSTRACT}

Current knowledge indicates that the mammalian target of rapamycin (mTOR) functions as two complexes, mTORC1 and MTORC2, regulating cell growth, proliferation, survival, differentiation, and motility. Recently $\mathrm{mSin} 1$ has been identified as a critical component of mTORC2, which is essential for phosphorylation of Akt and other signaling molecules. Studies have shown that rapamycin inhibits phosphorylation of mSin1. However, the underlying mechanism is unknown. Here we found that rapamycin inhibited phosphorylation of $\operatorname{mSin} 1$ potently and rapidly. Expression of rapamycin-resistant mutant of $\mathbf{m T O R}$ (MTOR-T), but not rapamycin-resistant and kinase dead mutant of mTOR (mTOR-TE), prevented rapamycin from inhibiting mSin 1 phosphorylation, suggesting that rapamycin-induced dephosphorylation of $\mathbf{m S i n} 1$ is mTOR-dependent. Surprisingly, ectopic expression of rapamycin-resistant and constitutively active p70 S6 kinase 1 (S6K1) did not confer resistance to rapamycininduced dephosphorylation of mSin1. Furthermore, disruption of mTORC1 and mTORC2 by silencing raptor and rictor, respectively, or downregulation of S6K1 or Akt did not induce the dephosphorylation of $\mathrm{mSin} 1$ as rapamycin did. However, silencing $\mathrm{mTOR}$ or mLST8 mimicked the effect of rapamycin, inhibiting mSin 1 phosphorylation. Our findings suggest that rapamycin inhibits $\mathrm{mSin} 1$ phosphorylation, which is independent of mTORC1 and mTORC2, but is possibly dependent on a new mTOR complex, which at least contains mTOR and mLST8.

\section{INTRODUCTION}

The mammalian target of rapamycin or the mechanistic target of rapamycin (mTOR), a member of the phosphoinositide-3' kinase (PI3K)-related kinase family, lies downstream of the type I insulin-like growth factor (IGF-1) receptor-PI3K $[1,2]$. Studies have demonstrated that mTOR functions at least as two complexes (mTORC1 and mTORC2) in mammalian cells $[1,2]$. mTORC1 contains mTOR, mLST8 (mammalian lethal with sec-13 protein 8 , also termed G-protein $\beta$-subunit-like protein, G $\beta \mathrm{L}$ ), PRAS40 (proline-rich Akt substrate $40 \mathrm{kDa}$ ) and raptor (regulatory-associated protein of mTOR) [3-9], whereas mTORC2 consists of mTOR, mLST8, rictor (rapamycin insensitive companion of mTOR), mSin1 (mammalian stress-activated protein kinase-interacting protein 1), and protor (protein observed with rictor) [10-16]. mTORC1 is sensitive to rapamycin, growth factors, energy, amino acids, stress and redox levels, and regulates cell growth and proliferation by controlling 
protein synthesis, lipid synthesis, and lysosome biogenesis through mediating phosphorylation of ribosomal p70 S6 kinase 1 (S6K1) and eukaryotic initiation factor 4E (eIF4E) binding protein 1 (4E-BP1) $[1,2]$. mTORC2 is only sensitive to prolonged $(>24 \mathrm{~h}$ ) rapamycin exposure in certain cases and growth factors, and regulates cell survival and cytoskeletal organization in part by regulating phosphorylation of Akt $[17,18]$, serum and glucocorticoid-inducible kinase 1 (SGK1) [19], protein kinase $\mathrm{C} \alpha(\mathrm{PKC} \alpha)[11]$ and focal adhesion proteins [10, $11,20]$, as well as the activity of small GTPases [10, 21, 22]. Both mTORC1 and mTORC2 interact with a negative regulator, DEPTOR (DEP domain containing mTORinteracting protein) [23], and a positive regulator, the Tti1/ Tel2 complex [24]. Though the functions of the mTOR complexes remain to be unveiled, current data indicate that mTOR plays a central role in the regulation of cell growth, proliferation, differentiation, survival, and motility, as well as angiogenesis and lymphangiogenesis [2, 25].

Mutations of MTOR gene have recently been found to be associated with the hyperactivation of mTOR in tumors [26-28]. High frequency of mutations of other components (such as PTEN, TSC, and PI3K) in mTOR signaling pathway has also been observed to link to human malignant progression and poor prognosis [2, 29, 30]. Interestingly, tumor cells with deregulated mTOR signaling are more sensitive to mTOR inhibitors, supporting that mTOR pathway is a promising target for cancer therapy. Rapamycin is the first identified inhibitor of mTOR. Unlike the new generation of ATP-competitive mTOR kinase inhibitors (such as AZD8055, INK 128, PP242, and Torin 2), rapamycin cannot directly bind to mTOR. Instead, it has to first form a complex with the cytosolic protein FK506 binding protein 12 (FKBP12) and then binds to the FKBP-binding (FRB) domain of mTOR, inhibiting certain functions of $\operatorname{mTOR}[1,2]$. While two rapamycin analogs (rapalogs), CCI-779 (Temsirolimus, Wyeth) and RAD001 (Everolimus, Novatis), have been approved by the US Food and Drug Administration (FDA) for treatment of metastatic renal cell carcinoma and advanced pancreatic neuroendocrine tumors, they only display modest anticancer efficacy in many other types of tumors [31]. It has been proposed that this is related to rapalogs activation of Akt and other survival pathways through insulin receptor substrate 1 (IRS-1)/ Grb10 feedback mechanisms [32-35]. However, in fact, the effects of rapalogs on Akt are complex. It has been described that prolonged $(24 \mathrm{~h})$ exposure to rapamycin (100 nM) caused activation of Akt in HeLa and H460 cells, weak inhibition in HEK-293T cells, and strong inhibition in PC-3 cells, although mTORC1-mediated S6K1 phosphorylation was completely blocked in all cases [18]. Therefore, the anticancer mechanism of rapamycin (or rapalogs) remains enigmatic.

In addition to inhibition of phosphorylation of S6K1 and 4E-BP1, rapamycin has recently been found to inhibit phosphorylation of rictor $[36,37]$ and $m \sin 1$ as well $[38,39]$. While the physiological significance of rictor or mSin 1 phosphorylation is under investigation, studies have revealed that S6K1 phosphorylates rictor (Thr1135), and rapamycin inhibition of this phosphorylation is by suppressing mTOR-mediated S6K1 [37]. To date, how rapamycin inhibits phosphorylation of $\mathrm{mSin} 1$ remains a mystery.

In this study, we found that rapamycin inhibited mSin1 phosphorylation in an mTOR kinase activitydependent manner. To our surprise, neither mTORC1 nor mTORC2 was involved in the regulation of $\mathrm{mSin} 1$ phosphorylation. However, silencing mTOR or mLST8 did mimic the effect of rapamycin, inhibiting $\mathrm{mSin} 1$ phosphorylation. Our results imply that rapamycin inhibits $\mathrm{mSin} 1$ phosphorylation possibly through targeting an unidentified third mTOR complex, which contains at least mTOR and mLST8.

\section{RESULTS}

\section{Rapamycin inhibits phosphorylation of mSin 1 in a concentration- and time-dependent manner}

To determine the effect of rapamycin on phosphorylation of $\mathrm{mSin} 1$, Rh1 cells, a rapamycinsensitive human Ewing sarcoma cell line [40, 41], were initially selected for the study. As there were no antibodies against phospho-mSin 1 available commercially, at the beginning, we detected phosphorylation of $\mathrm{mSin} 1$ according to the electrophoretic mobility of mSin 1 by Western blot analysis, as described by other groups $[38,39]$. As shown in Figure 1A, serum starvation for $24 \mathrm{~h}$ did not increase the electrophoretic mobility of $\mathrm{mSin} 1$ in Rh1 cells, but treatment of the serum-starved cells with rapamycin $(100 \mathrm{ng} / \mathrm{ml})$ for $24 \mathrm{~h}$ increased the electrophoretic mobility of mSin 1 obviously, regardless of stimulation with or without IGF-1 (10 ng/ml), suggesting that rapamycin might inhibit phosphorylation of $\mathrm{mSin} 1$. Furthermore, similar results were also observed in other cell lines, including human cervical cancer (HeLa), prostate cancer (PC-3), rhabdomyosarcoma (Rh30) cells and mouse embryonic fibroblasts (MEF) (Figure 1A and 1B), demonstrating that rapamycin inhibition of $\mathrm{mSin} 1$ phosphorylation is not cell line-dependent. To verify the electrophoretic mobility of $\mathrm{mSin} 1$ is correlated to its phosphorylation status, shrimp alkaline phosphatase (SAP) was used. We found that treatment of Rh30 cell lysates with SAP for $30 \mathrm{~min}$ reversed the mobility of $\mathrm{mSin} 1$ in the control (data not shown) or IGF-1-treated cells to that of rapamycin-treated cells (Figure 1B), revealing that the increased $\mathrm{mSin} 1$ mobility shift was indeed due to its dephosphorylation. In addition, rapamycin inhibition of mSin 1 phosphorylation was further confirmed by ${ }^{32} \mathrm{P}$-labeling (Figure 1C, 1D). 


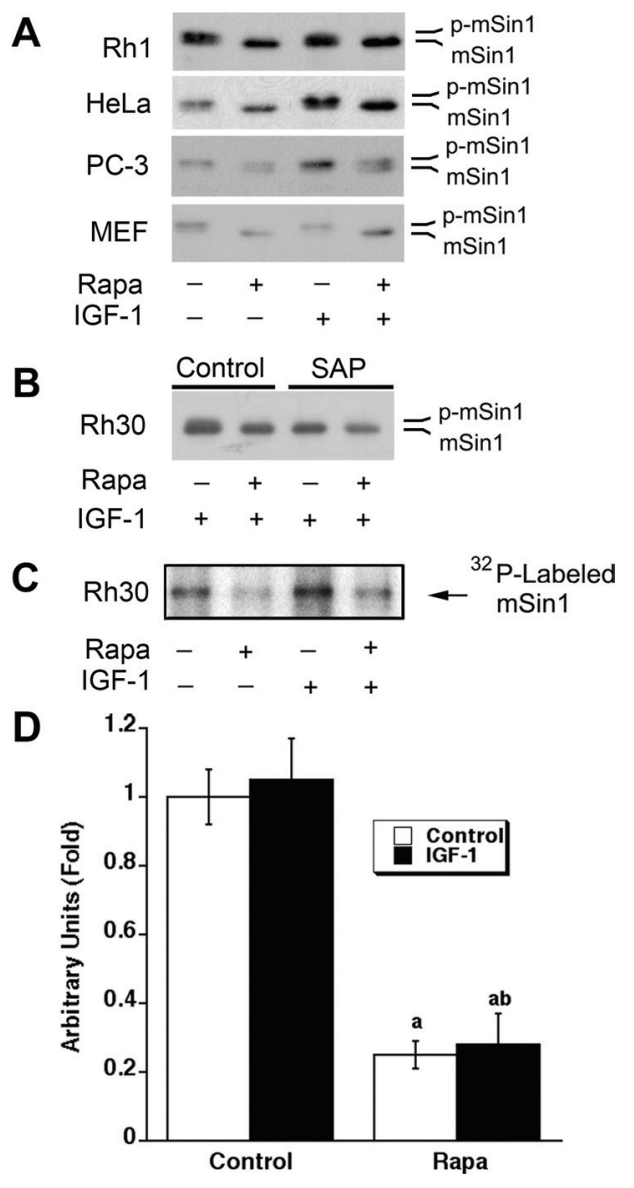

Figure 1: Rapamycin inhibits phosphorylation of mSin1. (A) Indicated cells were serum-starved for $24 \mathrm{~h}$, pretreated with rapamycin (Rapa, $100 \mathrm{ng} / \mathrm{ml}$ ) for $2 \mathrm{~h}$, and then stimulated with or without IGF-1 (10 ng/ml) for $22 \mathrm{~h}$, followed by Western blotting with mSin 1 antibody. (B) Rh30 cells were treated as described in (A). The whole cell lysates were treated with or without shrimp alkaline phosphatase (SAP) for $30 \mathrm{~min}$, and then analyzed by Western blotting with mSin1 antibody. (C) Rh30 cells were labeled with $\left.{ }^{32} \mathrm{P}\right]$ orthophosphate, followed by autoradiography, as described in "Materials and methods". (D) Quantification data for panel $(\mathrm{C})$. ${ }^{\mathrm{a}} P<0.05$, difference vs control group; ${ }^{b} P<0.05$, difference vs IGF-1 group.

To better understand the inhibitory effect of rapamycin on $\mathrm{mSin} 1$ phosphorylation, dose-response and time-course experiments were carried out. We found that when serum-starved Rh30 cells were pretreated with rapamycin $(0-1,000 \mathrm{ng} / \mathrm{ml})$ for $2 \mathrm{~h}$, and then stimulated with or without IGF-1 $(10 \mathrm{ng} / \mathrm{ml})$ for 10 $h$, as expected, rapamycin inhibited the basal or IGF-1stimulated phosphorylation of 4E-BP1 and S6K1, two best characterized downstream effector molecules of mTOR in a concentration-dependent manner (Figure 2A). Of interest, rapamycin also inhibited phosphorylation of $\mathrm{mSin} 1$ in a similar manner. Noticeably, rapamycin was able to increase $\mathrm{mSin} 1$ mobility shift at a very low concentration (0.05 ng/ml) (Figure 2A). Similarly, when the cells were pretreated with rapamycin $(100 \mathrm{ng} / \mathrm{ml})$ for $0-24 \mathrm{~h}$, and then stimulated with or without IGF-1 (10 ng/ml) for $15 \mathrm{~min}$, rapamycin was also found to be able to inhibit the basal or IGF-1-stimulated phosphorylation of mSin 1 in a timedependent manner. The inhibitory effect was rapid and remarkable within $2 \mathrm{~h}$ treatment (Figure 2B).

\section{Rapamycin inhibits phosphorylation of $\mathrm{mSin} 1$ in an mTOR kinase activity-dependent manner}

It has been described that rapamycin inhibits skeletal myogenesis in an mTOR kinase activity-independent manner [42, 43], although this remains controversial $[44,45]$. To determine whether rapamycin inhibition of mSin 1 phosphorylation depends on the kinase activity of mTOR, serum-starved Rh30 cells were infected with recombinant adenoviruses expressing empty vector (GFP), FLAG-tagged rapamycin-resistant kinase active mTOR (S2035T, mTOR-T), and rapamycin-resistant kinasedead mTOR (S2035T/D2357E, mTOR-TE), respectively. Subsequently, the cells were pre-treated with or without rapamycin for $2 \mathrm{~h}$, and then stimulated with IGF-1 (10 ng/ $\mathrm{ml}$ ) for $10 \mathrm{~h}$. Consistent with our previous observations $[20,21]$, expression of mTOR-T, but not mTOR-TE or GFP, potently prevented rapamycin from inhibiting phosphorylation of 4E-BP1 and S6K1 (Figure 3A), two best-characterized substrates of $\operatorname{mTOR}[1,2]$. Of note, 


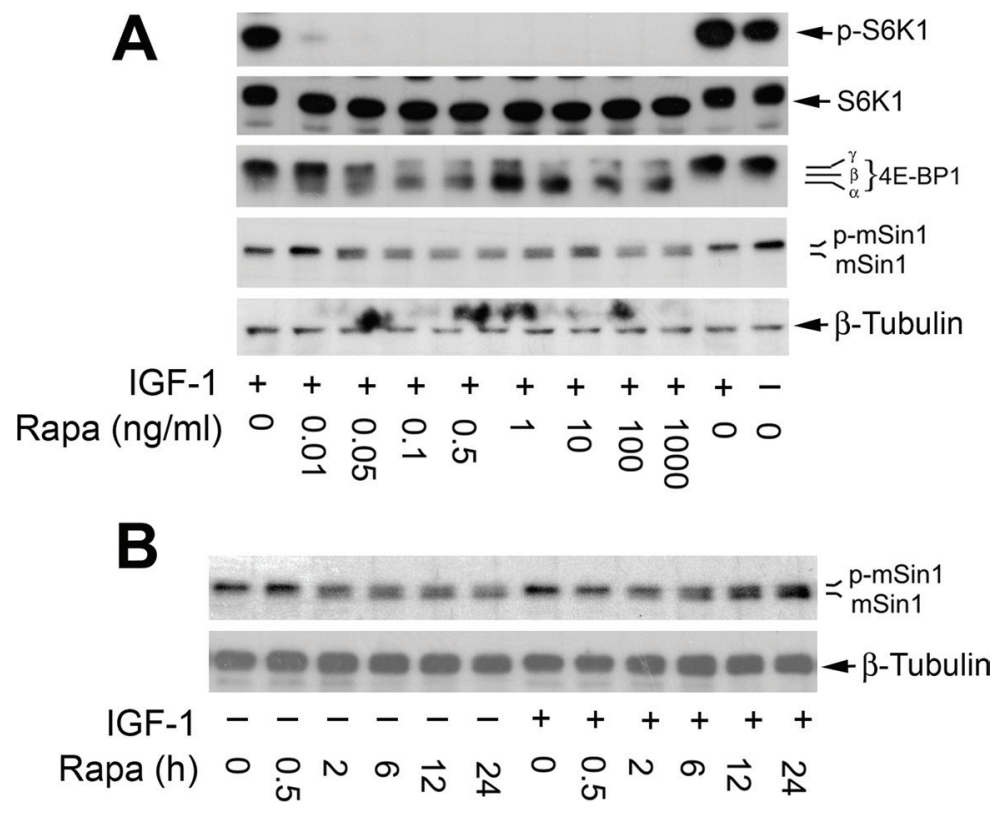

Figure 2: Rapamycin inhibits phosphorylation of $\mathbf{m S i n} 1$ in a concentration and time-dependent manner. Serum-starved Rh30 cells were pretreated with rapamycin for $2 \mathrm{~h}$ at indicated concentrations, and then stimulated with IGF-1 (10 ng/ml) for $10 \mathrm{~h}$ (A) or pretreated with $100 \mathrm{ng} / \mathrm{ml}$ rapamycin for indicated time, and then stimulated with or without IGF-1 (10 ng/ml) for $15 \mathrm{~min}$ (B). Treated cells were harvested for Western blotting with indicated antibodies.
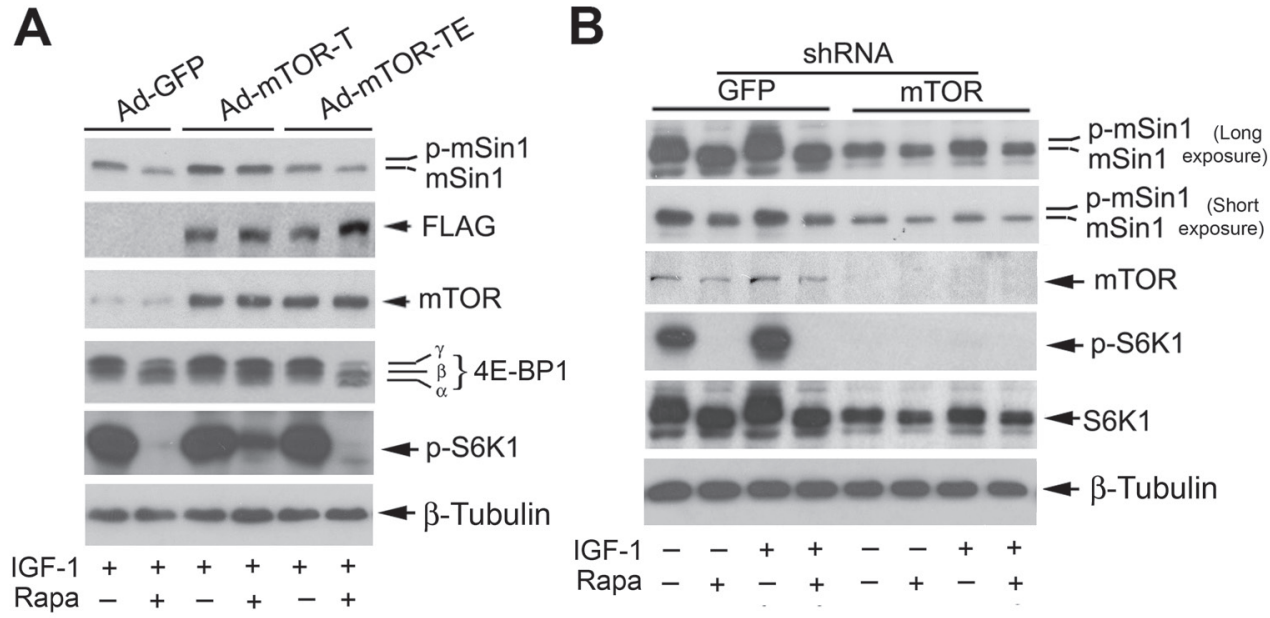

Figure 3: Rapamycin-induced dephosphorylation of $\mathrm{mSin} 1$ is dependent on mTOR kinase activity. Rh30 cells, infected with recombinant adenoviruses expressing GFP (Ad-GFP), FLAG-tagged rapamycin-resistant and kinase active mTOR (S2035T, Ad-mTOR-T), and rapamycin-resistant and kinase dead mTOR (S2035T/D2357E, Ad-mTOR-TE) (A) or with lentiviral shRNAs to GFP and mTOR (B) respectively, were serum-starved for $24 \mathrm{~h}$. The cells were then pretreated with or without rapamycin (Rapa, $100 \mathrm{ng} / \mathrm{ml})$ for $2 \mathrm{~h}$, and further stimulated with or without IGF-1 (10 ng/ml) for $10 \mathrm{~h}$, followed by Western blotting with indicated antibodies.

the phosphorylation state of 4E-BP1 was detected with an antibody to 4E-BP1. Rapamycin inhibited phosphorylation of 4E-BP1, as indicated by the decrease in the intensity of the uppermost band $\gamma$ and by the increase in the higher mobility band $\alpha$ and $\beta$ that corresponds to a less phosphorylated form of $4 \mathrm{E}-\mathrm{BP} 1$. The results indicate that mTOR-T functioned as a rapamycin-resistant and kinase active mutant, and mTOR-TE as a kinase-dead mutant in Rh30 cells. Interestingly, expression of mTOR-T, but not
mTOR-TE or GFP, conferred high resistance to rapamycin inhibition of mSin1 phosphorylation (Figure 3A), suggesting that rapamycin inhibits phosphorylation of $\mathrm{mSin} 1$ in an mTOR kinase activity-dependent manner.

We also substantiated the above finding using RNA interference. As expected, silencing mTOR dramatically decreased the mTOR kinase activity, since the basal or IGF-1-stimulated phosphorylation of S6K1 (Thr389), routinely used as an indicator of $\mathrm{mTOR}$ kinase activity 
$[1,2]$, was almost not detectable by Western blotting (Figure 3B). Of importance, silencing mTOR remarkably reduced the basal or IGF-1-simulated phosphorylation of $\mathrm{mSin} 1$, even in the absence of rapamycin (Figure 3B). Collectively, our results indicate that mTOR regulates phosphorylation of $\mathrm{mSin} 1$.

\section{Rapamycin inhibits phosphorylation of $\mathbf{m S i n} 1$ not via targeting S6K1}

Both rictor and $\mathrm{mSin} 1$ are the components of mTORC2 [1, 2], and S6K1 has recently been identified as the kinase that phosphorylates rictor (Thr1135) $[37,46$, 47]. Particularly, it has been described that $\mathrm{mSin} 1$ can be phosphorylated on T86 and T398 by S6K1 in a cellular context-dependent manner [48]. Therefore, at the very beginning, we hypothesized that rapamycin may inhibit mSin 1 phosphorylation by suppressing the activity of S6K1. To test this hypothesis, Rh30 cells were infected with recombinant adenovirus encoding constitutively active and rapamycin-resistant HA-tagged S6K1 mutant (F5A-E389-R3A) (Ad-S6K1-ca) and the control virus encoding GFP (Ad-GFP), respectively. In agreement with our previous data [49], expression of constitutively active and rapamycin-resistant (HA-S6K1-ca), but not GFP, increased the basal phosphorylation level of S6 ribosomal protein, a substrate of S6K1, and conferred resistance to rapamycin inhibition of S6 phosphorylation (Figure 4A), suggesting that the S6K1-ca was functional in the cells. However, expression of the rapamycinresistant constitutively active S6K1 failed to prevent rapamycin from inhibiting the phosphorylation of $\mathrm{mSin} 1$ (Figure 4A). The results suggest that rapamycin-induced dephosphorylation of $\mathrm{mSin} 1$ is probably not by inhibiting S6K1 activity.

To corroborate the above finding, S6K1 was silenced using lentiviral shRNA to S6K1. We found that infection with lentiviral shRNA to S6K1, but not the control shRNA to GFP, downregulated the protein level of S6K1 by $\sim 85 \%$ (vs. control), and abolished the basal or IGF-1-stimulated phosphorylation of S6K1, in Rh30 cells (Figure 4B), indicating the shRNA was working well in the cells. However, silencing S6K1 failed to reduce the basal or IGF-1-stimulated phosphorylation of $\mathrm{mSin} 1$, when rapamycin was absent (Figure 4B). The results support the notion that rapamycin-induced dephosphorylation (band shift) of $\mathrm{mSin} 1$ is independent of S6K1.

\section{Rapamycin inhibits phosphorylation of mSin1 independently of mTORC1}

mTORC1 is sensitive to rapamycin $[1,2]$. It is likely that rapamycin inhibits $\mathrm{mSin} 1$ phosphorylation by targeting other mTORC1-mediated signaling molecules, instead of S6K1. For this, we directly determined whether $\mathrm{mTORC} 1$ is responsible for the phosphorylation of mSin1. In consistence with our previous findings $[20,49]$, infection with lentiviral shRNA to raptor, but not the control shRNA to GFP, downregulated the protein level of raptor by $\sim 90 \%$ (vs. control) in Rh30 cells. Downregulation of raptor inhibited mTORC1mediated phosphorylation of S6K1 (Thr389), a surrogate for mTORC1 activity in the cells (Figure 5). However, downregulation of raptor did not inhibit the basal or IGF1 -stimulated phosphorylation of $\mathrm{mSin} 1$ as rapamycin did (Figure 5). The results demonstrate that rapamycin inhibits $\mathrm{mSin} 1$ phosphorylation, which is independent of mTORC1.

\section{Rapamycin inhibits mSin1 phosphorylation independently of mTORC2}

Currently, only two mTOR complexes, mTORC1 and mTORC2, have been identified [1, 2]. Since rapamycin-induced dephosphorylation of $\mathrm{mSin} 1$ was
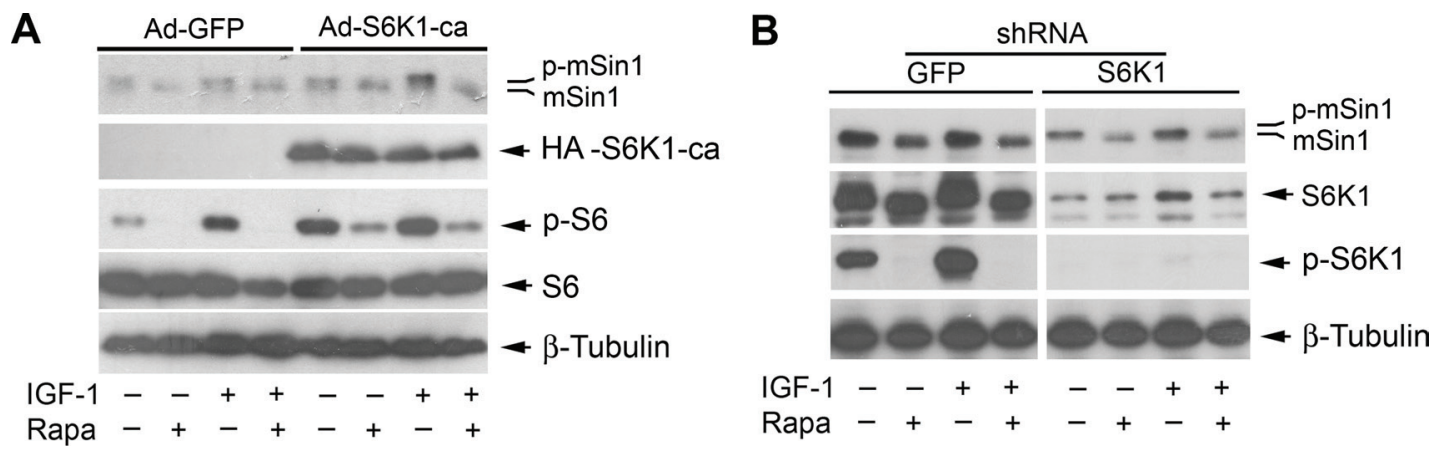

Figure 4: Rapamycin-induced dephosphorylation of $\mathbf{m S i n} 1$ is not by inhibiting S6K1. Rh30 cells, infected with recombinant adenoviruses expressing GFP (Ad-GFP) and HA-tagged rapamycin-resistant and constitutively active S6K1 (Ad-S6K1-ca) (A) or with lentiviral shRNAs to GFP and S6K1 (B) respectively, were serum-starved for $24 \mathrm{~h}$. The cells were then pretreated with or without rapamycin (Rapa, $100 \mathrm{ng} / \mathrm{ml}$ ) for $2 \mathrm{~h}$, and further stimulated with or without IGF-1 (10 ng/ml) for $10 \mathrm{~h}$, followed by Western blotting with indicated antibodies. 


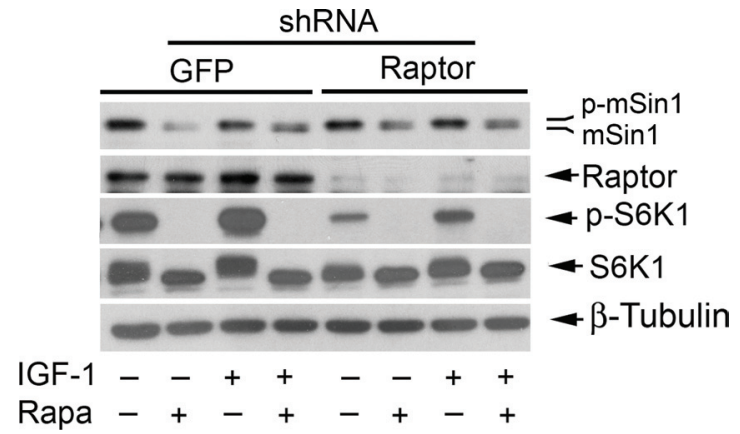

Figure 5: Rapamycin inhibits phosphorylation of mSin1 independently of mTORC1. Rh30 cells, infected with lentiviral shRNAs to GFP and raptor, respectively, were serum-starved for $24 \mathrm{~h}$. The cells were then pretreated with or without rapamycin (Rapa, 100 $\mathrm{ng} / \mathrm{ml})$ for $2 \mathrm{~h}$, and further stimulated with or without IGF-1 $(10 \mathrm{ng} / \mathrm{ml})$ for $10 \mathrm{~h}$, followed by Western blotting with indicated antibodies.

found to be independent of mTORC1 (Figure 5), next we turned to ask whether mTORC2 is involved in this event. To this end, mTORC2 was disrupted by silencing rictor. We found that infection with lentiviral shRNA to rictor, but not the control shRNA to GFP, downregulated the protein level of rictor by $\sim 90 \%$ (vs. control) in Rh30 cells. Downregulation of rictor inhibited the basal or IGF-1 stimulated phosphorylation of Akt (Ser473) in the cells (Figure 6A). In line with our previous results [20], rapamycin induced phosphorylation of Akt (Ser473) in Rh30 cells (Figure 6A), although it inhibited phosphorylation of S6K1 and 4E-BP1 (Figure 2). As rictor and $\mathrm{mSin} 1$ interact with and stabilize each other [12], downregulation of rictor also reduced the cellular protein level of $\mathrm{mSin} 1$ correspondingly (Figure 6A). However, downregulation of rictor did not inhibit the basal or IGF-1-stimulated phosphorylation of mSin1 as rapamycin did (Figure 6A). Moreover, silencing Akt, a major substrate of mTORC2, did not reduce phosphorylation of mSin 1 either (Figure 6B). The results indicate that rapamycin inhibits $\mathrm{mSin} 1$ phosphorylation independently of mTORC2 as well.

\section{mLST8 is essential for mTOR-mediated phosphorylation of $\mathbf{m S i n} 1$}

As mLST8 is an essential component for all mTOR complexes identified so far $[1,2]$, next we investigated whether the phosphorylation of $\mathrm{mSin} 1$ requires the involvement of mLST8. For this, Rh30 cells were infected with lentiviral shRNA to mLST8 or GFP (as a control). As illustrated in Figure 7A, mLST8 was downregulated by $\sim 80 \%$, in Rh30 cells by the lentiviral shRNA to mLST8. Silencing mLST8, like silencing mTOR (Figure 3B), inhibited the basal and IGF-1-stimulated phosphorylation of $\mathrm{mSin} 1$, even in the absence of rapamycin. Similar results were observed in HeLa cells (Figure 7B). The results indicate that mLST8 is necessary for mTORmediated phosphorylation of mSin1.

\section{DISCUSSION}

mTOR functions as two complexes, mTORC1 and mTORC2, regulating cell growth, proliferation, survival, differentiation and motility $[1,2]$. While intensive studies have focused on mTORC1, the mTORC2 signaling is only at the beginning to be recognized. Rictor and $\mathrm{mSin} 1$ interact with and stabilize each other, and are crucial for the integrity and the function of mTORC2 [12]. In addition to inhibiting mTORC1-mediated phosphorylation of S6K1 and 4E-BP1, rapamycin has recently been found to inhibit phosphorylation of rictor $[36,37]$ and $\mathrm{mSin} 1$ as well $[38,39]$. Studies have revealed that S6K1 phosphorylates rictor (Thr1135), and rapamycin inhibition of rictor (Thr1135) phosphorylation is through suppressing S6K1 $[37,46,47]$. However, so far, how rapamycin inhibits mSin1 phosphorylation remains largely unknown. Here we show that rapamycin inhibited $\mathrm{mSin} 1$ phosphorylation in an mTOR kinase activity-dependent manner. This is supported by the observations that 1) expression of rapamycin-resistant kinase active mTOR (mTOR-T), but not rapamycin-resistant kinase dead mTOR (mTOR-TE), prevented rapamycin inhibition of $\mathrm{mSin} 1$ phosphorylation; and 2) silencing mTOR also inhibited mSin1 phosphorylation. Our findings strongly support the notion that mTOR regulates phosphorylation of $\mathrm{mSin} 1$.

To elucidate the molecular mechanism whereby rapamycin inhibits $\mathrm{mSin} 1$ phosphorylation, at the very beginning, we were focusing on S6K1, since S6K1 has been found to phosphorylate $\mathrm{mSin} 1$ on Thr86 and Thr398 [48]. However, in this study, we found that S6K1, in spite of being highly sensitive to rapamycin, was not involved in rapamycin-induced dephosphorylation of $\mathrm{mSin} 1$. This is evidenced by the findings that ectopic expression of rapamycin-resistant and constitutively active S6K1 (S6K1-ca) did not confer obvious resistance to rapamycininduced dephosphorylation of $\mathrm{mSin} 1$, and silencing S6K1 did not induce the electrophoretic mobility of $\mathrm{mSin} 1$ as rapamycin did. 
A

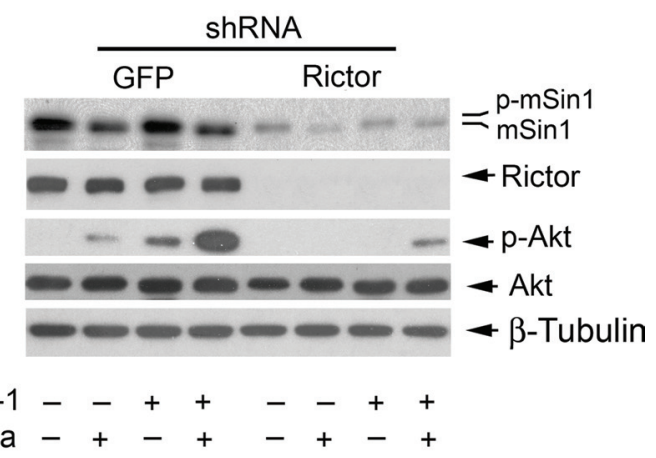

B

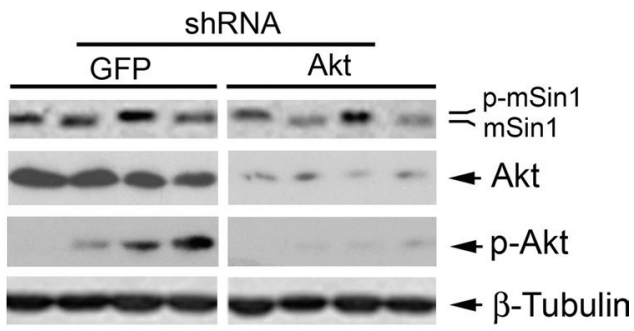

IGF-1 - $-++-\quad++$

Rapa -+-+-+-+

Figure 6: Rapamycin inhibits phosphorylation of $\mathbf{m S i n} 1$ independently of mTORC2. Rh30 cells, infected with lentiviral shRNAs to GFP and rictor (A) or GFP and Akt (B) respectively, were serum-starved for $24 \mathrm{~h}$. The cells were then pretreated with or without rapamycin (Rapa, $100 \mathrm{ng} / \mathrm{ml}$ ) for $2 \mathrm{~h}$, and further stimulated with or without IGF-1 (10 ng/ml) for $10 \mathrm{~h}$, followed by Western blotting with indicated antibodies.

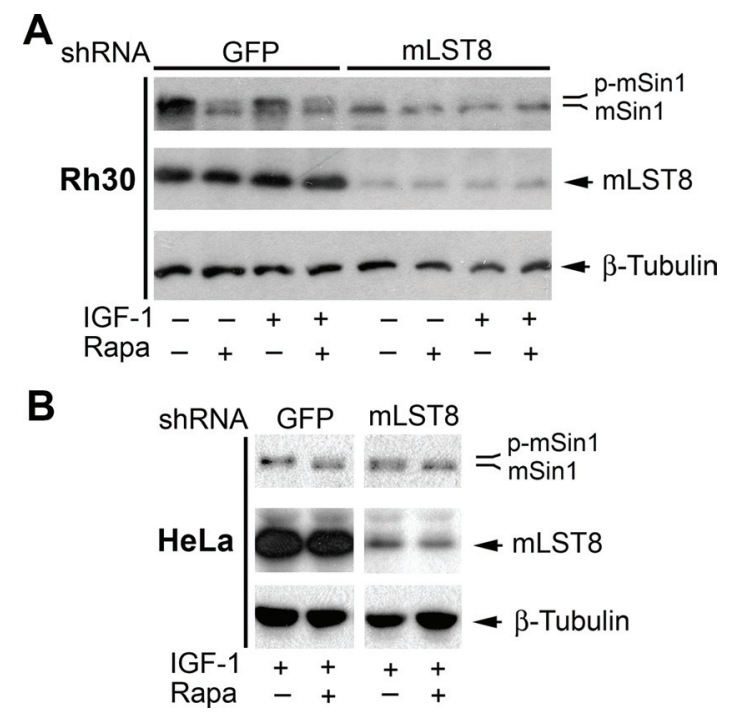

Figure 7: mLST8 is essential for mTOR-mediated phosphorylation of mSin1. Rh30 (A) or HeLa cells (B) infected with lentiviral shRNAs to GFP and mLST8, respectively, were serum-starved for $24 \mathrm{~h}$. The cells were then pretreated with or without rapamycin (Rapa, $100 \mathrm{ng} / \mathrm{ml})$ for $2 \mathrm{~h}$, and further stimulated with or without IGF-1 $(10 \mathrm{ng} / \mathrm{ml})$ for $10 \mathrm{~h}$, followed by Western blotting with indicated antibodies.

As rapamycin inhibited $\mathrm{mSin} 1$ phosphorylation within $2 \mathrm{~h}$ (Figure 2B), and mTORC1 is sensitive to acute rapamycin treatment $[1,2]$, we next reasoned that rapamycin-induced dephosphorylation of $\mathrm{mSin} 1$ is most likely by targeting mTORC1, although mTOR-mediated S6K1 pathway had been ruled out in this event (Figure 4). It has been described that rapamycin inhibits mTORC1, resulting in activation protein phosphatase $2 \mathrm{~A}(\mathrm{PP} 2 \mathrm{~A})$ [50]. Possibly, rapamycin inhibits phosphorylation of mSin 1 by activation of PP2A. However, out of our expectation, disruption of $\mathrm{mTORC} 1$ by silencing raptor did not inhibit mSin1 phosphorylation as rapamycin did (Figure 5), pointing out that the rapamycin-induced dephosphorylation of $\mathrm{mSin} 1$ is not mediated by mTORC1. 
Although S6K1-mediated phosphorylation of rictor (Thr1135) does not affect mTORC2 integrity or in vitro kinase activity, it causes an increase in 14-3-3 binding to rictor and mTORC2-dependent phosphorylation of Akt (Ser473) in cells [37, 46, 47], suggesting a potential crosstalk between mTORC1 and mTORC2. After demonstrating that mSin 1 phosphorylation is independent of mTORC1, we further examined whether this is dependent on mTORC2, although mTORC2 is only sensitive to prolonged rapamycin treatment in certain cases [18]. However, surprisingly, disruption of mTORC2 by silencing rictor failed to induce the electrophoretic mobility of $\mathrm{mSin} 1$ as rapamycin did, suggesting that rapamycininduced dephosphorylation of $\mathrm{mSin} 1$ is independent of mTORC2 as well. This is further supported by the observation that downregulation of Akt, a major substrate of mTORC2, did not induce the electrophoretic mobility of $\mathrm{mSin} 1$ as rapamycin did. However, interestingly, silencing mTOR or mLST8 (a component shared by all mTOR complexes) recapitulated the effect of rapamycin on the phosphorylation of $\mathrm{mSin} 1$. Our results imply that rapamycin inhibits $\mathrm{mSin} 1$ phosphorylation possibly through targeting an unidentified third mTOR complex, which contains at least mTOR and mLST8. Hall group has reported that in addition to TORC1 and TORC2, actually TOR can interact with numerous proteins, as a 2-megadalton TOR protein complex has been detected by gel filtration [7]. Recently, a new TOR complex, which contains TOR, LST8 and Armadillo domain-containing protein (TbArmtor), has been identified in the parasite, Trypanosoma brucei [52]. Further research is needed to unveil whether there exists a similar counterpart in mammalian cells, and whether it mediates mSin 1 phosphorylation.

Recently, it has been found that $\mathrm{mSin} 1$ can be phosphorylated on Thr86 and Thr398 by either Akt or S6K in a cell-dependent manner $[48,51]$. Interestingly, the phosphorylation of $\mathrm{mSin} 1$ on both Thr86 and Thr398, but not on Thr86 alone, is required for the integrity and the activity of mTORC $2[48,51]$. In the present study, we found that downregulation of S6K1 or Akt failed to increase the electrophoretic mobility (dephosphorylation) of $\mathrm{mSin} 1$ under our experimental conditions, suggesting that rapamycin induced the band shift of $\mathrm{mSin} 1$ possibly by inducing dephosphorylation of more other residues. In consistence with our previous observation [20], here we found that rapamycin induced phosphorylation of Akt (Ser473) in Rh30 cells, but inhibited phosphorylation of mSin1 (Figure 6). Our results indicate that the Akt phosphorylation may be independent of rapamycininduced dephosphorylation of $\mathrm{mSin} 1$.

mTOR is regulated by multiple upstream factors including growth factors and nutrients such as glucose and amino acids $[1,2]$. In response to growth factors deprivation or nutrients starvation, mTORC1 can be inhibited, which may lead to reduced protein/lipid synthesis, inhibiting cell growth and inducing autophagy
$[1,2]$. It has been demonstrated that the small GTPase Rheb (Ras homolog enriched in brain) directly interacts with and activates mTOR [53]. Tuberous sclerosis complex $1 / 2$ (TSC1/2), a tumor suppressor, acts as a GTPaseactivating protein (GAP) for Rheb [54-57]. Growth factors or hormones (e.g. IGF-1 and insulin) activate mTORC 1 by inhibiting TSC $1 / 2$ function $[1,2]$. Hence, in response to growth factors deprivation or serum-starvation, mTORC1 activity is reduced in normal cells, but remains constitutively active in TSC-mutant cells [30]. Under glucose starvation (low ATP) condition, AMP-activated protein kinase (AMPK) can be activated [58]. Activated AMPK can inhibit mTORC1 signaling via activation of TSC1/2 and induce phosphorylation of raptor (Ser792) [59, 60]. Recently, it has been found that Rag small GTPases relay signals from amino acids to activate mTORC1 [61-63]. Amino acid starvation inhibits Rag-Ragulator mediated translocation of mTORC1 to lysosomal membranes, preventing mTORC1 activation [30].

In the present study, we noticed that serumstarvation or stimulation with IGF-1 did not affect the electrophoretic mobility of mSin1 (Figure 1A and 1B), but IGF-1 was found to slightly increase phosphorylation of $\mathrm{mSin} 1$ by ${ }^{32} \mathrm{P}$-labeling (Figure $1 \mathrm{C}$ ). Rapamycin was able to increase the electrophoretic mobility of $\mathrm{mSin} 1$ in a spectrum of cell lines (Rh1, Rh30, PC-3, HeLa and MEF), regardless of presence or absence of IGF-1 (Figure 1A and 1B). The results suggest that only one or a few residues on $\mathrm{mSin} 1$ are sensitive to IGF-1-stimulated phosphorylation, but more residues are independent of growth factors for mTOR-mediated phosphorylation. It is known that mTORC1 is sensitive to rapamycin, growth factors, energy, amino acids, stress and redox levels [1, 2], whereas mTORC2 is only sensitive to prolonged $(>24 \mathrm{~h})$ rapamycin exposure in certain cases and growth factors [18]. Our observation implies that the unidentified third mTOR complex may be different from mTORC1 or mTORC2, which is sensitive to rapamycin, but may be insensitive to growth factors. Further research is required to address this issue. Recently, it has been described that mTOR stabilizes $\mathrm{mSin} 1$ by phosphorylating its hydrophobic and conserved Ser260 site to maintain the integrity of mTORC2 [64]. Also, glucose deprivation or acute ATP depletion, but not amino acid deprivation, prevents the mTOR-dependent phosphorylation of mSin1 on Ser260 and Akt on Thr450 in cells [64], further suggesting that mTOR may regulate phosphorylation of $\mathrm{mSin} 1$ on unique residues, in response to specific environmental cues. Therefore, it would be of great importance to unveil whether the new mTOR complex is sensitive to energy (glucose or ATP), amino acids, stress and redox levels, and whether it is evolutionally conserved from yeast to mammals.

In summary, here, for the first time, we have shown that rapamycin inhibited $\mathrm{mSin} 1$ phosphorylation, which were not through inhibiting either mTORC1/S6K1 or mTORC2/Akt pathway (Figure 8). However, silencing 

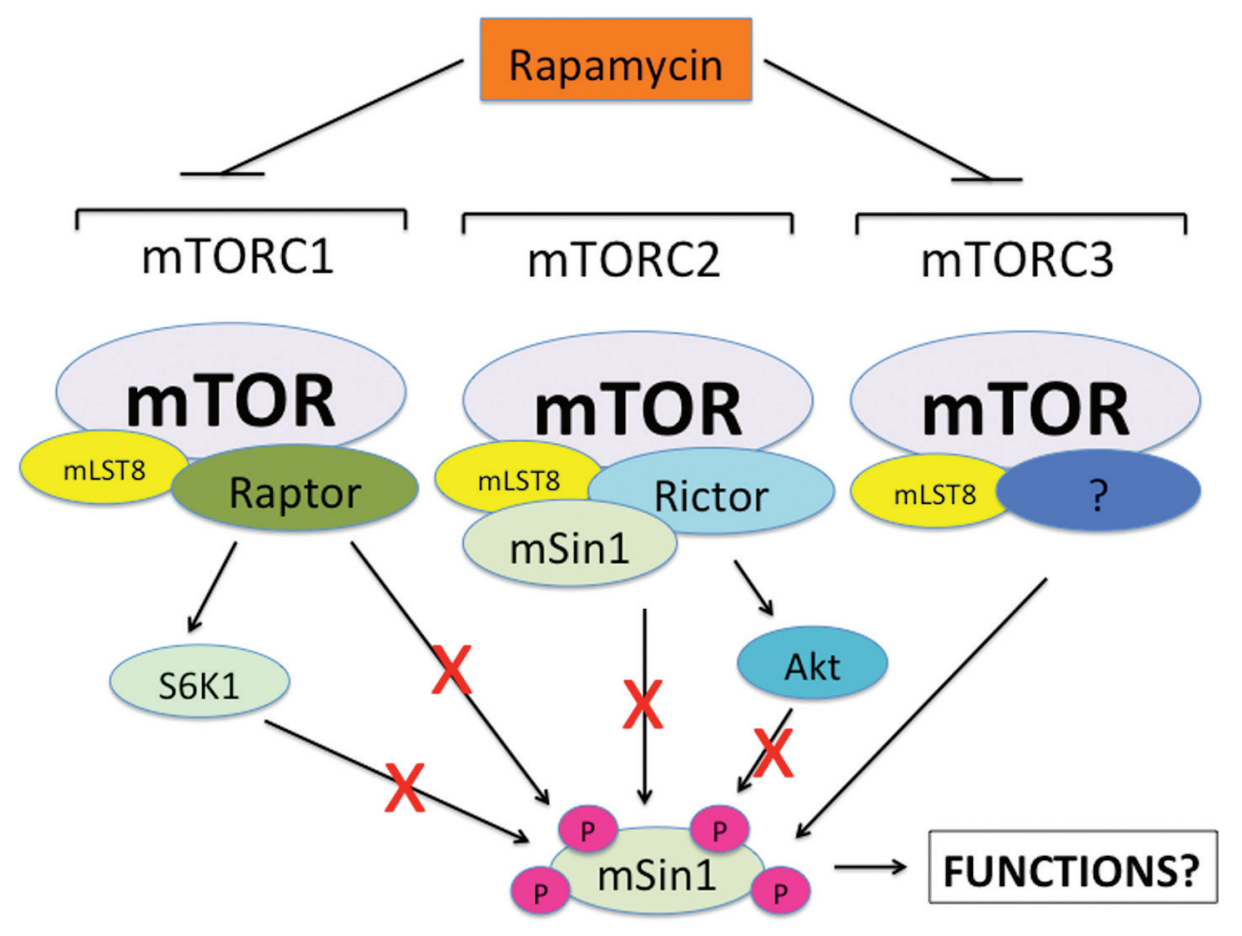

Figure 8: A proposed model showing how rapamycin inhibits mSin1 phosphorylation. Neither mTORC1/S6K1 nor mTORC2/Akt was found to be involved in the regulation of mSin1 phosphorylation. However, silencing mTOR or mLST8 inhibited the phosphorylation of $\mathrm{mSin} 1$ as rapamycin did. Thus, we propose that rapamycin may inhibit mSin 1 phosphorylation by targeting an unidentified third mTOR complex (mTORC3) that contains at least mTOR and mLST8.

mTOR or mLST8 was able to inhibit the phosphorylation of $\mathrm{mSin} 1$ as rapamycin did. Our findings suggest that rapamycin may inhibit $\mathrm{mSin} 1$ phosphorylation probably by targeting an unidentified third mTOR complex (mTORC3) that contains at least mTOR and mLST8 (Figure 8). Further efforts are needed to identify this new complex, and to determine the phosphorylation site(s) of $\mathrm{mSin} 1$ as well as the physiological significance of the mSin1 phosphorylation.

\section{MATERIALS AND METHODS}

\section{Materials}

Rapamycin (LC Laboratories, Woburn, MA) was dissolved in dimethyl sulfoxide (DMSO) to prepare a $100 \mu \mathrm{g} / \mathrm{ml}$ stock solution and stored at $-20^{\circ} \mathrm{C}$. IGF1 (PeproTech, Rocky Hill, NJ) was rehydrated in 0.1 $\mathrm{M}$ acetic acid to prepare a $10 \mu \mathrm{g} / \mathrm{ml}$ stock solution and stored at $-80^{\circ} \mathrm{C}$. Shrimp alkaline phosphatase $(1,000$ units/ml, New England BioLabs, Ipswich, MA). Enhanced chemiluminescence solution was from Pierce (Rockford, IL). Antibodies included those against mTOR, S6K1, Akt, S6, HA (Santa Cruz Biotechnology, Santa Cruz, CA), phospho-S6K1 (Thr389), phosphoAkt (Ser473), phospho-S6 (Ser/235/236), 4E-BP1 (Cell Signaling, Beverly, MA), raptor, rictor (Bethyl Laboratories, Montgomery, TX), mLST8 (GenWay
Biotech, San Diego, CA), mSin1 (for Western blotting, K87 [13]; for immunoprecipitation, sc-48588, Santa Cruz Biotechnology), $\beta$-tubulin, FLAG (Sigma, St. Louis, MO); goat anti-rabbit IgG-horseradish peroxidase (HRP), goat anti-mouse IgG-HRP, rabbit anti-goat IgG-HRP, and goat anti-chicken IgG-HRP (Pierce). All other chemicals were purchased from Sigma.

\section{Cell culture}

Human rhabdomyosarcoma Rh30 and Ewing sarcoma Rh1 cells were generously provided by Dr. Peter J. Houghton (Nationwide Children's Hospital, Columbus, $\mathrm{OH}$ ), and grown in antibiotic-free RPMI 1640 medium (Mediatech, Herndon, VA) supplemented with 10\% fetal bovine serum (FBS) (Hyclone, Logan, UT). Human cervical adenocarcinoma (HeLa), prostate adenocarcinoma (PC-3) (American Type Culture Collection, Manassas, VA), and wild-type (wt) mouse embryonic fibroblasts (MEF) [13] were grown in antibiotic-free Dulbecco's Modified Eagle Medium (DMEM) (Mediatech) supplemented with 10\% FBS. Human embryonic kidney (HEK) 293 (American Type Culture Collection), 293A, and 293T cells (Invitrogen, Carlsbad, CA) were grown in antibiotic-free DMEM supplemented with 10\% heat-inactivated FBS. All cell lines were grown in a humidified incubator at $37^{\circ} \mathrm{C}$ in an atmosphere of $5 \% \mathrm{CO}_{2}$. For experiments where cells were deprived of serum, cell monolayers were washed 
with phosphate buffered saline (PBS), and incubated in the serum-free DMEM for at least $24 \mathrm{~h}$.

\section{Recombinant adenoviral constructs and infection of cells}

The recombinant adenoviruses expressing the green fluorescence protein (GFP) (Ad-GFP), FLAGtagged rapamycin-resistant and kinase active mTOR (S2035T, mTOR-T) (Ad-mTOR-T), rapamycin-resistant and kinase dead mTOR (S2035T/D2357E, mTOR-TE) (Ad-mTOR-TE), and HA-tagged rapamycin-resistant and constitutively active mutant of S6K1 (F5A-E389-R3A) (Ad-S6K1-ca) were generated as described previously [20, 21, 49]. All adenoviruses were amplified, titrated and used as described [49].

\section{Lentiviral shRNA constructs and infection of cells}

To generate lentiviral shRNA to human Akt1, oligonucleotides containing the target sequences were synthesized, annealed and inserted into FSIPPW lentiviral vector via the EcoR1/BamH1 restriction enzyme site. Oligonucleotides used were: sense, 5'-AATTCCCCGTGAGGCTCCCCTCAACATGCAAGA GATGTTGAGG GGAGCCTCACGTTTTTG-3', and antisense, GATCCAAAAACGTGAGGCTCCCCTCA ACATCTCTTGCATGTTGAGGGGAGCCTCACGGGG3'. Lentiviral shRNAs to GFP, mTOR, raptor, rictor and S6K1 were described previously [20]. Lentiviruses expressing indicated shRNAs were produced and titrated as described [49]. Cells, when grown to $\sim 70 \%$ confluence, were infected with the above lentiviral shRNAs in the presence of $8 \mu \mathrm{g} / \mathrm{ml}$ polybrene and exposed to $2 \mu \mathrm{g} / \mathrm{ml}$ puromycin after $24 \mathrm{~h}$ of infection. In 5 days, cells were used for experiments.

\section{Western blotting}

Cells were seeded in 6-well plates in appropriate medium containing $10 \%$ FBS. Next day, the cells were serum-starved in DMEM for $24 \mathrm{~h}$, and then treated with or without rapamycin $(100 \mathrm{ng} / \mathrm{ml})$ for indicated time, followed by stimulation with or without IGF-1 $(10 \mathrm{ng} / \mathrm{ml})$ for indicated time. Western blotting was performed using indicated antibodies, as described previously [49].

\section{Detection of mSin 1 phosphorylation by ${ }^{32} \mathrm{P}$ labeling}

Cells, grown in 100-mm dishes, were pretreated with or without rapamycin $(100 \mathrm{ng} / \mathrm{ml})$ for $24 \mathrm{~h}$. Subsequently, the used medium was replaced with $3 \mathrm{ml}$ phosphate-free DMEM (Invitrogen), and the cells were then stimulated with or without IGF-1 $(10 \mathrm{ng} / \mathrm{ml})$ for
$1 \mathrm{~h}$, followed by labeling with $\left[{ }^{32} \mathrm{P}\right]$ orthophosphate $(0.4$ $\mathrm{mCi} / \mathrm{ml}$ ) (MB Biomedicals, Solon, $\mathrm{OH}$ ) for $4 \mathrm{~h}$ at $37^{\circ} \mathrm{C}$. The cells were finally lysed in RIPA buffer [50 mM Tris, pH 7.2; $150 \mathrm{mM} \mathrm{NaCl} ; 1 \%$ sodium deoxycholate; $0.1 \%$ SDS; $1 \%$ Triton-X 100; $10 \mathrm{mM} \mathrm{NaF} ; 1 \mathrm{mM} \mathrm{Na} \mathrm{VO}_{4}$; protease inhibitor cocktail (1:1000, Sigma)], followed by immunoprecipitation with antibodies to $\mathrm{mSin} 1$ (sc-48588, Santa Cruz Biotechnology). The immunoprecipitates were separated by SDS-PAGE and the gel was dried. Phosphorylation of $\mathrm{mSin} 1{ }^{32} \mathrm{P}$-labeled $\left.\mathrm{mSin} 1\right)$ was detected by autoradiography. The bands were semiquantified using NIH image J.

\section{Statistical analysis}

Results were expressed as mean values \pm standard error (mean \pm S.E.). Statistical analysis was performed using student $t$-test or one-way analysis of variance (ANOVA) followed by post hoc Dunnett's test for multiple comparisons. A level of $P<0.05$ was considered to be significant.

\section{ACKNOWLEDGMENTS}

This work was supported in part by NIH grant R01 CA115414 (S. H.), American Cancer Society Award (RSG08-135-01-CNE (S. H.), and National Natural Science Foundation of China (No. 81102473, Y. L.), and Applied and Basic Research Project of Department of Science and Technology of Sichuan Province (No. 2015JY0149, M. Y.).

\section{REFERENCES}

1. Huo Y, Iadevaia V, Proud CG. Differing effects of rapamycin and mTOR kinase inhibitors on protein synthesis. Biochem Soc Trans. 2011; 39:446-450.

2. Laplante M, Sabatini DM. mTOR Signaling in Growth Control and Disease. Cell. 2012; 149:274-293.

3. Fonseca BD, Smith EM, Lee VH, Mackintosh C, Proud CG. PRAS40 is a target for mammalian target of rapamycin complex 1 and is required for signaling downstream of this complex. J Biol Chem. 2007; 282:24514-24524.

4. Hara K, Maruki Y, Long X, Yoshino K, Oshiro N, Hidayat S, Tokunaga C, Avruch J, Yonezawa K. Raptor, a binding partner of target of rapamycin (TOR), mediates TOR action. Cell. 2002; 110:177-189.

5. Kim DH, Sarbassov DD, Ali SM, King JE, Latek RR, Erdjument-Bromage H, Tempst P, Sabatini DM. mTOR interacts with raptor to form a nutrient-sensitive complex that signals to the cell growth machinery. Cell. 2002; 110:163-175.

6. Kim DH, Sarbassov DD, Ali SM, Latek RR, Guntur KV, Erdjument-Bromage H, Tempst P, Sabatini DM. GbetaL, a positive regulator of the rapamycin-sensitive pathway required for the nutrient-sensitive interaction between raptor and mTOR. Mol Cell. 2003; 11:895-904. 
7. Loewith R, Jacinto E, Wullschleger S, Lorberg A, Crespo JL, Bonenfant D, Oppliger W, Jenoe P, Hall MN. Two TOR complexes, only one of which is rapamycin sensitive, have distinct roles in cell growth control. Mol Cell. 2002; 10:457-468.

8. Sancak Y, Thoreen CC, Peterson TR, Lindquist RA, Kang SA, Spooner E, Carr SA, Sabatini DM. PRAS40 is an insulin-regulated inhibitor of the mTORC1 protein kinase. Mol Cell. 2007; 25:903-915.

9. Vander Haar E, Lee SI, Bandhakavi S, Griffin TJ, Kim DH. Insulin signalling to mTOR mediated by the Akt/PKB substrate PRAS40. Nat Cell Biol. 2007; 9:316-323.

10. Jacinto E, Loewith R, Schmidt A, Lin S, Rüegg MA, Hall A, Hall MN. Mammalian TOR complex 2 controls the actin cytoskeleton and is rapamycin insensitive. Nat Cell Biol. 2004; 6:1122-1128.

11. Sarbassov DD, Ali SM, Kim DH, Guertin DA, Latek RR, Erdjument-Bromage H, Tempst P, Sabatini DM. Rictor, a novel binding partner of $\mathrm{mTOR}$, defines a rapamycininsensitive and raptor-independent pathway that regulates the cytoskeleton. Curr Biol. 2004; 14:1296-1302.

12. Frias MA, Thoreen CC, Jaffe JD, Schroder W, Sculley T, Carr SA, Sabatini DM. mSin1 is necessary for Akt/PKB phosphorylation, and its isoforms define three distinct mTORC2s. Curr Biol. 2006; 16:1865-1870.

13. Jacinto E, Facchinetti V, Liu D, Soto N, Wei S, Jung SY, Huang Q, Qin J, Su B. SIN1/MIP1 maintains rictor-mTOR complex integrity and regulates Akt phosphorylation and substrate specificity. Cell. 2006; 127:125-137.

14. Yang Q, Inoki K, Ikenoue T, Guan KL. Identification of $\mathrm{Sin} 1$ as an essential TORC2 component required for complex formation and kinase activity. Genes Dev. 2006; 20:2820-2832.

15. Pearce LR, Huang $X$, Boudeau J, Pawłowski R, Wullschleger S, Deak M, Ibrahim AF, Gourlay R, Magnuson MA, Alessi DR. Identification of Protor as a novel Rictor-binding component of mTOR complex-2. Biochem J. 2007; 405:513-522.

16. Woo SY, Kim DH, Jun CB, Kim YM, Haar EV, Lee SI, Hegg JW, Bandhakavi S, Griffin TJ, Kim DH. PRR5, a novel component of mTOR complex 2, regulates plateletderived growth factor receptor beta expression and signaling. J Biol Chem. 2007; 282:25604-25612.

17. Sarbassov DD, Guertin DA, Ali SM, Sabatini DM. Phosphorylation and regulation of Akt/PKB by the rictormTOR complex. Science. 2005; 307:1098-1101.

18. Sarbassov DD, Ali SM, Sengupta S, Sheen JH, Hsu PP, Bagley AF, Markhard AL, Sabatini DM. Prolonged rapamycin treatment inhibits mTORC2 assembly and Akt/ PKB. Mol Cell. 2006; 22:159-168.

19. García-Martínez JM, Alessi DR. mTOR complex 2 (mTORC2) controls hydrophobic motif phosphorylation and activation of serum- and glucocorticoid-induced protein kinase 1 (SGK1). Biochem J. 2008; 416:375-385.
20. Liu L, Chen L, Chung J, Huang S. Rapamycin inhibits F-actin reorganization and phosphorylation of focal adhesion proteins. Oncogene. 2008; 27:4998-5010.

21. Liu L, Luo Y, Chen L, Shen T, Xu B, Chen W, Zhou H, Han X, Huang S. Rapamycin inhibits cytoskeleton reorganization and cell motility by suppressing RhoA expression and activity. J Biol Chem. 2010; 285:38362-38373.

22. Gulhati P, Bowen KA, Liu J, Stevens PD, Rychahou PG, Chen M, Lee EY, Weiss HL, O'Connor KL, Gao T, Evers BM. mTORC1 and mTORC2 regulate EMT, motility, and metastasis of colorectal cancer via RhoA and Rac1 signaling pathways. Cancer Res. 2011; 71:3246-3256.

23. Peterson TR, Laplante M, Thoreen CC, Sancak Y, Kang SA, Kuehl WM, Gray NS, Sabatini DM. DEPTOR is an mTOR inhibitor frequently overexpressed in multiple myeloma cells and required for their survival. Cell. 2009; 137:873-886.

24. Kaizuka T, Hara T, Oshiro N, Kikkawa U, Yonezawa K, Takehana K, Iemura S, Natsume T, Mizushima N. Tti1 and Tel2 are critical factors in mammalian target of rapamycin complex assembly. J Biol Chem. 2010; 285:20109-20116.

25. Luo Y, Liu L, Rogers D, Su W, Odaka Y, Zhou H, Chen W, Shen T, Alexander JS, Huang S. Rapamycin inhibits lymphatic endothelial cell tube formation by downregulating vascular endothelial growth factor receptor 3 protein expression. Neoplasia. 2012; 14:228-237.

26. Gerlinger M, Rowan AJ, Horswell S, Larkin J, Endesfelder D, Gronroos E, et al. Intratumor heterogeneity and branched evolution revealed by multiregion sequencing. N Engl J Med. 2012; 366:883-892.

27. Grabiner BC, Nardi V, Birsoy K, Possemato R, Shen K, Sinha S, Jordan A, Beck AH, Sabatini DM. A diverse array of cancer-associated MTOR mutations are hyperactivating and can predict rapamycin sensitivity. Cancer Discov. 2014; 4:554-563.

28. Wagle N, Grabiner BC, Van Allen EM, Hodis E, Jacobus S, Supko JG, Stewart M, Choueiri TK, Gandhi L, Cleary JM, Elfiky AA, Taplin ME, Stack EC, Signoretti S, Loda M, Shapiro GI, Sabatini DM, Lander ES, Gabriel SB, Kantoff PW, Garraway LA, Rosenberg JE. Activating mTOR mutations in a patient with an extraordinary response on a phase I trial of everolimus and pazopanib. Cancer Discov. 2014; 4:546-553.

29. Dazert E, Hall MN. mTOR signaling in disease. Curr Opin Cell Biol. 2011; 23:744-755.

30. Inoki K, Kim J, Guan KL. AMPK and mTOR in cellular energy homeostasis and drug targets. Annu Rev Pharmacol Toxicol. 2012; 52:381-400.

31. Zhang YJ, Duan Y, Zheng XF. Targeting the mTOR kinase domain: the second generation of mTOR inhibitors. Drug Discov Today. 2011; 16:325-331.

32. Sun SY, Rosenberg LM, Wang X, Zhou Z, Yue P, Fu H. Activation of Akt and eIF4E survival pathways by rapamycin-mediated mammalian target of rapamycin inhibition. Cancer Res. 2005; 65:7052-7058. 
33. O'Reilly KE, Rojo F, She QB, Solit D, Mills GB, Smith D, Lane H, Hofmann F, Hicklin DJ, Ludwig DL, Baselga J, Rosen N. mTOR inhibition induces upstream receptor tyrosine kinase signaling and activates Akt. Cancer Res. 2006; 66:1500-1508.

34. Hsu PP, Kang SA, Rameseder J, Zhang Y, Ottina KA, Lim D, Peterson TR, Choi Y, Gray NS, Yaffe MB, Marto JA, Sabatini DM. The mTOR-regulated phosphoproteome reveals a mechanism of mTORC1-mediated inhibition of growth factor signaling. Science. 2011; 332:1317-1322.

35. Yu Y, Yoon SO, Poulogiannis G, Yang Q, Ma XM, Villén J, Kubica N, Hoffman GR, Cantley LC, Gygi SP, Blenis J. Phosphoproteomic analysis identifies Grb10 as an mTORC1 substrate that negatively regulates insulin signaling. Science. 2011; 332:1322-1326.

36. Akcakanat A, Singh G, Hung MC, Meric-Bernstam F. Rapamycin regulates the phosphorylation of rictor. Biochem Biophys Res Commun. 2007; 362:330-333.

37. Dibble CC, Asara JM, Manning BD. Characterization of Rictor phosphorylation sites reveals direct regulation of mTOR complex 2 by S6K1. Mol Cell Biol. 2009; 29:5657-5670.

38. Rosner M, Hengstschläger M. Cytoplasmic and nuclear distribution of the protein complexes mTORC1 and mTORC2: rapamycin triggers dephosphorylation and delocalization of the mTORC2 components rictor and sin1. Hum Mol Genet. 2008; 17:2934-2948.

39. Chen $\mathrm{CH}$, Sarbassov dos D. The mTOR (mammalian target of rapamycin) kinase maintains integrity of mTOR complex 2. J Biol Chem. 2011; 286:40386-40394.

40. Smith MA, Morton CL, Phelps D, Girtman K, Neale G, Houghton PJ. SK-NEP-1 and Rh1 are Ewing family tumor lines. Pediatr Blood Cancer. 2008; 50:703-706.

41. Hosoi H, Dilling MB, Shikata T, Liu LN, Shu L, Ashmun RA, Germain GS, Abraham RT, Houghton PJ. Rapamycin causes poorly reversible inhibition of mTOR and induces p53-independent apoptosis in human rhabdomyosarcoma cells. Cancer Res. 1999; 59:886-894.

42. Erbay E, Chen J. The mammalian target of rapamycin regulates $\mathrm{C} 2 \mathrm{C} 12$ myogenesis via a kinase-independent mechanism. J Biol Chem. 2001; 276:36079-36082.

43. Ge Y, Wu AL, Warnes C, Liu J, Zhang C, Kawasome H, Terada N, Boppart MD, Schoenherr CJ, Chen J. mTOR regulates skeletal muscle regeneration in vivo through kinase-dependent and kinase-independent mechanisms. Am J Physiol Cell Physiol. 2009; 297:C1434-C1444.

44. Shu L, Zhang X, Houghton PJ. Myogenic differentiation is dependent on both the kinase function and the N-terminal sequence of mammalian target of rapamycin. J Biol Chem. 2000; 277:16726-16732.

45. Shu L, Houghton PJ. The mTORC2 complex regulates terminal differentiation of $\mathrm{C} 2 \mathrm{C} 12$ myoblasts. Mol Cell Biol. 2009; 29:4691-4700.
46. Julien LA, Carriere A, Moreau J, Roux PP. mTORC1activated S6K1 phosphorylates Rictor on threonine 1135 and regulates mTORC2 signaling. Mol Cell Biol. 2010; 30:908-921.

47. Treins C, Warne PH, Magnuson MA, Pende M, Downward $\mathrm{J}$. Rictor is a novel target of p70 S6 kinase-1. Oncogene. 2010; 29:1003-1016.

48. Liu P, Gan W, Inuzuka H, Lazorchak AS, Gao D, Arojo O, Liu D, Wan L, Zhai B, Yu Y, Yuan M, Kim BM, Shaik S, Menon S, Gygi SP, Lee TH, Asara JM, Manning BD, Blenis J, Su B, Wei W. Sin1 phosphorylation impairs mTORC2 complex integrity and inhibits downstream Akt signalling to suppress tumorigenesis. Nat Cell Biol. 2013; 15:1340-1350.

49. Liu L, Li F, Cardelli JA, Martin KA, Blenis J, Huang S. Rapamycin inhibits cell motility by suppression of mTORmediated S6K1 and 4E-BP1 pathways. Oncogene. 2006; 25:7029-7040.

50. Peterson RT, Desai BN, Hardwick JS, Schreiber SL. Protein phosphatase 2A interacts with the $70-\mathrm{kDa}$ S6 kinase and is activated by inhibition of FKBP12rapamycinassociated protein. Proc Natl Acad Sci USA. 1999; 96:4438-4442.

51. Humphrey SJ, Yang G, Yang P, Fazakerley DJ, Stöckli J, Yang JY, James DE. Dynamic adipocyte phosphoproteome reveals that Akt directly regulates mTORC2. Cell Metab. 2013; 17:1009-1020.

52. Barquilla A, Saldivia M, Diaz R, Bart JM, Vidal I, Calvo E, et al. Third target of rapamycin complex negatively regulates development of quiescence in Trypanosoma brucei. Proc Natl Acad Sci USA. 2012; 109:14399-14404.

53. Long X, Lin Y, Ortiz-Vega S, Yonezawa K, Avruch J. Rheb binds and regulates the mTOR kinase. Curr Biol. 2005; 15:702-713.

54. Garami A, Zwartkruis FJ, Nobukuni $T$, Joaquin $M$, Roccio M, Stocker H, Kozma SC, Hafen E, Bos JL, Thomas G. Insulin activation of Rheb, a mediator of $\mathrm{mTOR} / \mathrm{S} 6 \mathrm{~K} / 4 \mathrm{E}-\mathrm{BP}$ signaling, is inhibited by TSC1 and 2. Mol Cell. 2003; 11:1457-1466.

55. Inoki K, Li Y, Xu T, Guan KL. Rheb GTPase is a direct target of TSC2 GAP activity and regulates mTOR signaling. Genes Dev. 2003; 17:1829-1834.

56. Tee AR, Manning BD, Roux PP, Cantley LC, Blenis J. Tuberous sclerosis complex gene products, Tuberin and Hamartin, control mTOR signaling by acting as a GTPaseactivating protein complex toward Rheb. Curr Biol. 2003; 13:1259-1268.

57. Zhang Y, Gao X, Saucedo LJ, Ru B, Edgar BA, Pan D. Rheb is a direct target of the tuberous sclerosis tumour suppressor proteins. Nat. Cell Biol. 2003; 5:578-581.

58. Hardie DG. AMP-activated/SNF1 protein kinases: conserved guardians of cellular energy. Nat Rev Mol Cell Biol. 2007; 8:774-785. 
59. Corradetti MN, Inoki K, Bardeesy N, DePinho RA, Guan KL. Regulation of the TSC pathway by LKB1: evidence of a molecular link between tuberous sclerosis complex and Peutz-Jeghers syndrome. Genes Dev. 2004; 18:1533-1538.

60. Gwinn DM, Shackelford DB, Egan DF, Mihaylova MM, Mery A, Vasquez DS, Turk BE, Shaw RJ. AMPK phosphorylation of raptor mediates a metabolic checkpoint. Mol Cell. 2008; 30:214-226.

61. Sancak Y, Peterson TR, Shaul YD, Lindquist RA, Thoreen CC, Bar-Peled L, Sabatini DM. The Rag GTPases bind raptor and mediate amino acid signaling to mTORC1. Science. 2008; 320:1496-14501.
62. Kim E, Goraksha-Hicks P, Li L, Neufeld TP, Guan KL. Regulation of TORC1 by Rag GTPases in nutrient response. Nat Cell Biol. 2008; 10:935-945.

63. Sancak Y, Bar-Peled L, Zoncu R, Markhard AL, Nada S, Sabatini DM. Ragulator-Rag complex targets mTORC1 to the lysosomal surface and is necessary for its activation by amino acids. Cell. 2010; 141:290-303.

64. Chen CH, Kiyan V, Zhylkibayev AA, Kazyken D, Bulgakova O, Page KE, Bersimbaev RI, Spooner E, Sarbassov dos D. Autoregulation of the mechanistic target of rapamycin (mTOR) complex 2 integrity is controlled by an ATP-dependent mechanism. J Biol Chem. 2013; 288:27019-27030. 